\title{
Predict organizational citizenship behavior of the staff based on the factors of the psychological capital and staff of Ministry of Sport and Youth
}

\author{
Khaidan HATMI, Mohhammad Reza ESMAEILI, Sayed Hamid SAJADI \\ ${ }^{1}$ Department of Sport Management, Tehran Central Branch, Islamic Azad University, Tehran, Iran. \\ Address correspondence to K. Hatmi, e-mail: hatami.khid@gmail.com
}

\begin{abstract}
The aim of the present study was to predict organizational citizenship behavior of the staff of the Ministry of Sport and Youth in the west part of the country based on the factors of the psychological capital. The research methodology employed in the present study was applied and practical. The population consisted of all employees in the departments of the ministry of Sport and Youth in the west part of the country in the year 1394 including 266 personnel among whom 165 ones were selected as samples. In order to collect information, for collecting data on the psychological capital variable, the psychological capital questionnaire was used, and to collect data on the organizational citizenship behavior variable, the organizational citizenship behavior questionnaire was used. For data analysis, Kolmogorov-Smirnov inferential statistics were used to determine the normal distribution of data and the analysis of variance. The results of the study showed that there was a significant relationship between psychological capital and its components and organizational citizenship behavior. And the examination of the predictor variables showed that optimism, self-efficacy, and resilience $(\mathrm{P} \leq 0.05)$ can significantly explain the citizenship behavior variance.
\end{abstract}

Keywords: Organizational citizenship behavior, psychological capital, staff of the Ministry of Sport and Youth.

\section{INTRODUCTION}

Until the last decade, the close and deep relationship between the two major fields of humanities; namely, organizational behavior management and psychology was focused on mitigating the psychological complications of human resources in work environments. Through this approach, issues such as unmotivated staff, displacement, absence, and deviant behaviors attracted a lot of attention from researchers, particularly Martin Seligman, the famous psychologist (6). Based on his studies and those of other researchers in the field of behavioral science, significant results were obtained concerning effective cures for inefficient organizational behaviors (9). However, the thing that wasn't considered was the healthy mental aspect of individuals. Filling this gap was the beginning of a new approach called 'positive psychology' and 'positive organizational behavior' $(6,29)$. Luthans $(16)$ as the founder of this field of behavioral science in management, defines it as "positive organizational behavior is the study and application of positive aspects and strengths of psychology so that these aspects can be measured, developed, and managed and utilized to improve the performance of the individual". The positive psychological capital is an important new concept in the field of positive organizational behavior in a way that many scholars emphasize the importance of conceptualizing and measuring positive psychology in the organization and argue that positive human resources and the mental assets of the organization are highly effective in improving the performance of the organization $(19,20)$. Luthans et al. (19) define psychological capital as the positive mental status of an individual in development and improvement which includes the following four aspects: selfefficacy, optimism, hope, and resilience. Self-efficacy refers to the level of self-confidence and certainty of the part of the individual in performing challenging 
tasks and taking the necessary steps for success. Optimism means having positive standards regarding success in the present and future. Hope is defined as having the perseverance for reaching the goals and changing the course if necessary. Finally, resilience is defines as maintaining the mental balance and the ability to revert to the natural state in case of facing problems and difficulties (19). F. Luthans \& Youssef (17) consider human capital, social capital, and positive psychological capital as the three aspects of human resources. Based on this view, human capital includes the knowledge and know-how accessible to human resources; social capital includes networks, values, and trust among individuals; and positive psychological capital includes the mental capabilities of individuals which are measurable and can be developed and managed in order to improve performance. Therefore, psychological capital involves the realization of positive organizational behavior criteria in a way that people's willingness and their preparedness for improvement and development is increased, which in turn improves their performance. In any case, the nature of the aspects of psychological capital indicates that psychological capital can have a positive relationship with citizenship behavior.

Luthans \& Youssef (18) argue that people with a high level of resiliency will have higher job satisfaction, happiness in the work environment, and organizational commitment and they will also have a higher individual outcome.

Overall, the previous studies indicate that this positive variable along with self-efficacy, hope, and optimism, affects the behaviors of individuals and in turn their performance in the working environment (19).

However, it should be noted that the performance of individuals in the success of organizations in today's complicated world is not solely based on their behaviors and their role performance; rather, the organization also needs meta-role behaviors which reflect the commitment of individuals to its long-term success (22).

In the related literature, there is much attention given to the identification of meta-role behaviors among the employees and it is assumed that these behaviors have a significant impact on organizational performance. The majority of these behaviors can be considered as organizational citizenship behaviors. Organizational citizenship behavior is an individuallevel behavior which is carried out arbitrarily and voluntarily; however, the organization's official reward system cannot identify it directly and obviously and it generally improves the effectiveness of the organization's performance (25). Therefore, organizational citizenship behavior is a behavior performed by the employees which is beyond the individual's mandatory tasks. Hence, it is considered as a completely optional and voluntarily behavior and it is not rewarded based on the official structure of the organization's compensation system (14).

Therefore, the main difference between the organizational citizenship behavior and behaviors related to the role and duty is that the organizational citizenship behavior is completely voluntary and it is beyond the official expectations for the individual's role and tasks (1). In the literature, various types of organizational citizenship behaviors are identified. For instance, Podsakoff et al. (27) identified more than thirty types of organizational citizenship behavior. Pierce et al. (26) listed some of the common features in all organizational citizenship behaviors, which include: being voluntary, being conscious, being positive, and profiting the organization and all the coworkers. The important point is that if there are negative and undesirable attitudes among the employees, the level of organizational citizenship behavior will be very low (15). Organizational citizenship behavior determines the preparedness of employees for working and trying in performing organizational tasks in order to participate in improving productivity, customers' satisfaction, and improving quality. Improving the level of organizational citizenship behaviors indicates the willingness and interest of employees in accepting change and utilizing new management methods (12). Generally, organizations have concluded that effective performance depends on the fact that employees try and work beyond their official job descriptions (23). Baharifar et al. (4) carried out a study on the variables affecting citizenship behaviors and concluded that organizational justice affected citizenship behaviors through improving moral behaviors related to friendship and sportsmanship aspect. The study carried out by Avey et al. (3) on the positive results of psychological capital in the organization confirms its positive effects on performance as well as on reducing deviant behaviors.

In the study of Shahnawaz \& Jafri (32), quoting (35), in two public and private organizations, psychological capital is considered as a better predictor for organizational commitment and 
organizational citizenship behavior. Golparvar \& Rafizadeh (8) believe that leadership support and empowerment through improving the individual's attitude towards the job will lead to improving organizational citizenship behaviors. Moreover, there have been a lot of additional efforts for identifying the factors related to forming organizational citizenship behaviors and their results for the organization (7).

Some studies indicate the effects of intelligent on organizational citizenship behaviors (30), loyalty on organizational citizenship behaviors (31) and trust and organizational commitment on organizational citizenship behaviors (21). However, among these studies, the relationship between organizational citizenship behaviors and the variables of psychological capital, which is considered as a new capital in human resources for acquiring competitive advantage, has been neglected. Therefore, few studies have analyzed and discussed the effects of this capital on the components of organizational citizenship behaviors. The question is that whether witnessing such behaviors is affected by the psychological capital of each individual or not. And if so, which mental component has the highest impact on organizational citizenship behaviors?

\section{MATERIALS \& METHODS}

Since the main objective of the current study is to predict organizational citizenship behaviors based on the components of psychological capital, it is considered as an applied study which utilizes the correlation method. The statistical population of the study includes all the employees working in the General Offices for the Youth and Sports in Western Iran including four Provinces. The sample of the study includes 164 participants selected using stratified random sampling method.

The descriptive results of the study shows that among 164 participants, 42 participants (25\%) are single and 122 participants (75\%) are married. Moreover, the highest frequency regarding the age group is related to the age group of 31-35 years (25\%) and the lowest frequency is related to the age group lower than 25 years $(0.5 \%)$. Furthermore, the demographic features of the participants show that the highest frequency regarding the education level is related to bachelor's degree (58\%) and the lowest frequency is high school diploma $(2 \%)$.

\section{Measurement Tools}

\section{Psychological Capital Questionnaire}

In order to gather the required data related to the variable of psychological capital, the psychological capital inventory of Luthans et al. (19) was used. Luthans et al. (19) said that the Cronbach's Alpha for this questionnaire was 0.90. Moreover, Hoveyda \& Naderi (10) calculated the Cronbach's Alpha for this questionnaire as 0.87. This questionnaire has 24 six-option questions and the scoring of the options is based on Likert spectrum (completely agree $=6$ and completely disagree $=1$ ). This questionnaire measures psychological capital in four aspects which are presented in Table 1 below.

Table 1. The aspects of psychological capital questionnaire.

\begin{tabular}{llc}
\hline Variable & Components & Questions \\
\hline Psychological & Hope & $1-6$ \\
Capital & Optimism & $7-12$ \\
& Self-efficacy & $13-18$ \\
& Resiliency & $19-24$ \\
\hline
\end{tabular}

\section{Questionnaire for Organizational Citizenship Behavior}

In order to gather the required data related to the variable of organizational citizenship behaviors, the questionnaire of organizational citizenship behaviors developed by Podsakoff et al. (27) was used which includes twenty five-option questions whose scoring is based on Likert spectrum (Very high $=5$, and very low $=1$ ). This questionnaire is organized based on five categories of altruism, conscientiousness, sportsmanship, civic virtue, and respect and reverence. This questionnaire has been translated in Iran by Islami \& Sayar (11) and has been used in various studies. It has acceptable reliability and validity. In the study carried out by PursoltaniZarandi \& Amirji (28), the validity of this questionnaire was confirmed by utilizing corrections suggested by university professors of sports management. Through an experimental study on 30 sports teachers in Mashhad, the internal reliability of the questionnaire for organizational citizenship behaviors was calculated used Cronbach's Alpha coefficient to be 0.76 .

In order to determine the internal reliability of the questions in the questionnaires used in the current study, Cronbach's alpha coefficient was used. 
In order to do this, 164 employees in General Offices of the Youth and Sports in Western Iran including the four provinces completed the selected questionnaires. Then, these questionnaires were analyzed and for each one of the main variables of the study, Cronbach's Alpha coefficient was calculated, presented in Table 2. Considering the internal reliability coefficients presented in Table 2, the reliability of the measures was confirmed.

Table 2. Cronbach's alpha coefficients for the variables of the study.

\begin{tabular}{clc}
\hline Number & Variable & $\begin{array}{c}\text { Cronbach's } \\
\text { Alpha }\end{array}$ \\
\hline 1 & Psychological capital & 0.85 \\
2 & Organizational citizenship behavior & 0.79 \\
\hline
\end{tabular}

\section{Statistical Tests}

In order to analyze the obtained data in this study, descriptive and inferential statistical tests have been used in two separate sections. In the first section, the descriptive analysis of the data is presented in the form of frequency tables, means, and standard deviations. In the second section, the inferential statistical tests including Kolmogrov-Smirnov test for testing the normality of the data distribution, and the analysis of variance (ANOVA) test were used. All the statistical tests were carried out using SPSS software application version 16. Moreover, all the statistical tests were carried out in the significance level of $\alpha=$ 0.05 .

\section{RESULTS}

Table 3 presents the mean and standard deviation for the variables of psychological capital and citizenship behavior.
In order to investigate the relationship between the components of psychological capital and citizenship behaviors, simultaneous regression analysis was used. It is worth mentioning that the outlier values were omitted by the computer. The results of the analysis of variance related to the regression of citizenship behaviors on the components of psychological capital are presented in Table 4.

Table 3. Mean and standard deviation for the research variables.

\begin{tabular}{lcc}
\hline Variables & Mean & SD \\
\hline Psychological capital & 95.57 & 23.02 \\
Hope & 25.52 & 7.06 \\
Optimism & 24.39 & 6.58 \\
Self-efficacy & 22.55 & 5.60 \\
Resiliency & 23.12 & 6.47 \\
Citizenship behavior & 69.89 & 9.54 \\
Altruism & 14.85 & 2.93 \\
Conscientiousness & 10.09 & 2.17 \\
Sportsmanship & 9.86 & 2.46 \\
Virtue & 9.98 & 2.64 \\
Respect and reverence & 25.11 & 4.58 \\
\hline
\end{tabular}

Based on these results, the value of $F$ (16.255) is significant at $P \leq 0.01$ and $29 \%$ of the variance related to citizenship behavior is explained by the components of psychological capital $\left(R^{2}=0.289\right)$. Considering the significance of citizenship behavior's regression on psychological capital, the coefficients for the prediction equation are presented in Table 5 .

Table 4. Analysis of variance related to the regression of citizenship behaviors on the components of psychological capital.

\begin{tabular}{lccccccc}
\hline Variance source & $\begin{array}{c}\text { Sum of } \\
\text { squares }\end{array}$ & $d f$ & $\begin{array}{c}\text { Mean of } \\
\text { squares }\end{array}$ & F & p & $R$ & $R^{2}$ \\
\hline Regression & 4309.401 & 4 & 1077.350 & 16.255 & 0.001 & 0.538 & 0.289 \\
Remainder & 10604.635 & 160 & 66.279 & & & \\
Total & 14914.03 & 164 & & & & \\
\hline
\end{tabular}


Table 5. Coefficients of the prediction equation for citizenship behavior using psychological capital.

\begin{tabular}{lccccc}
\hline Model & B coefficients & SE & $\begin{array}{c}\text { Beta standard } \\
\text { coefficients }\end{array}$ & $t$ & $p$ \\
\hline Constant value & 52.622 & 2.795 & - & 18.830 & $0.001^{*}$ \\
Hope & 0.157 & 0.180 & 0.116 & 0.872 & 0.385 \\
Optimism & 0.491 & 0.198 & 0.338 & 2.474 & $0.014^{*}$ \\
Self-efficacy & 0.350 & 0.171 & 0.206 & 2.042 & $0.043^{*}$ \\
Resiliency & 0.397 & 0.172 & 0.269 & 2.309 & $0.022^{*}$ \\
\hline${ }^{*}$ p $<0.05$ & & & &
\end{tabular}

The regression coefficients for each one of the four predicting variables show that optimism, citizenship behavior, and resiliency $(P \leq 0.05)$ can significantly explain the variance of the citizenship behavior variable. The impact factor for optimism $(B=0.491)$ considering the $t$ statistic shows that optimism can predict the variations in citizenship behavior with $95 \%$ confidence. This impact factor is positive, which means that if we increase the optimism level by one unit, the individual's score for citizenship behavior will increase by 0.49 . Moreover, the impact factor for self-efficacy $(B=0.350)$ considering the $t$ statistic shows that the variable of self-efficacy can predict the variations in citizenship behavior with $95 \%$ confidence. This impact factor is positive, which means that if we increase the selfefficacy level by one unit, the individual's score for citizenship behavior will increase by 0.35 . Furthermore, the impact factor for resiliency $(B=$ 0.397) considering the $t$ statistic shows that the variable of resiliency can predict the variations in citizenship behavior with $95 \%$ confidence. This impact factor is positive, which means that if we increase the resiliency level by one unit, the individual's score for citizenship behavior will increase by 0.39 .

\section{DISCUSSION}

The results show that there is a significant relationship between psychological capital and its components and organizational citizenship behavior. Therefore, the null hypothesis is rejected and the hypothesis is confirmed, so it can be said that psychological capital and its components have a positive significant relationship with organizational citizenship behavior. The results of the current study regarding the relationship between psychological behavior and its components and organizational citizenship behavior are in line with the results of Zhang (36), the results of Shahnawaz \& Jafri (32), the results of Avey et al. (2) and the findings of Avey et al. (3) regarding the effects of psychological capital on personal and organizational citizenship behaviors, the study of Mahmoudi-Meymand \& Harandi (22) regarding the effects of self-efficacy on citizenship behaviors, and a part of the research model presented by Norman et al. (24).

The presence of a relationship between psychological capital and its components and organizational citizenship behavior indicates that psychological capital is considered one of the health factors related to organizational citizenship behavior in any society and in fact it is the necessary condition for establishing organizational citizenship behavior (33). Organizational citizenship behavior of a satisfied employee indicates his or her response to those who value him or her and in a higher level, this will lead to job satisfaction, which in turn improves the motivation for presenting desirable organizational citizenship behavior (5).

Considering these findings, it can be inferred that witnessing meta-role behaviors, whose outcomes for the performance and the organization have been proved by multiple studies, will be affected by the positive mental characteristics of individuals, the most effective of which is resiliency considering the selected sample of the current study. Based on the results, the higher the management ability of the individual under difficult conditions and in the presence of conflicts and clashes in the working environment (resiliency), the higher the likelihood of an individual presenting behaviors beyond his or her ordinary responsibilities and tasks. Based on the results it can be concluded that the higher levels of self-confidence will make the individual believe that his or her job accomplishments are due to his or her own capabilities, which increases the individuals' psychological capital. This higher psychological 
capital will indirectly affect the expression of responsibility and individual cooperation (altruism) or group cooperation with others (civic virtue). There is no doubt that individuals enter the organization with various levels of psychological capital. Based on the results of the current study, it can be claimed that the higher the levels of this capital, particularly the four positive variables measured in individuals, the higher the likelihood of presenting organizational citizenship behaviors. This necessitates the focus of the organizations during the hiring process as well as measuring the aspects of psychological capital along with other individual capitals in job interviews. On the other hand, as mentioned in defining the components of psychological capital, these positive components are not relatively constant like personality traits; rather, they can be improved to advance the performance of the organization. Improving the positive mental components among current employees, such as hope, will improve the future meta-role behaviors and reduce deviant behaviors and in turn counterproductive work behaviors (CWBs) in the organization. It should be noted that training assessments in modern organizations must not be solely based on job requirements and personality traits; rather, the positive mental characteristics of individuals should also be evaluated and their level of psychological capital upon their entrance into the organization and in the course of their career must also be appraised since these evaluations will inform the organization regarding the future problematic behaviors and increase the likelihood of behaviors such as altruism, civil virtue, and working conscience. Moreover, it is expected that using mental capital and citizenship behaviors simultaneously, as emphasized in this study, can lead to synergy due to the latent capitals of individuals in the organization.

\section{REFERENCES}

1. Allison BJ, Voss RS, Dryer S. Student classroom and career success: the role of organizational citizenship behavior. Journal of Education for Business, 2001; 76(2): 282-288.

2. Avey JB, Luthans F, Youssef CM. The additive value of positive psychological capital in predicting work attitudes and behaviors. Journal of Management, 2009; 36(2): 430-452.

3. Avey JB, Nimnicht JL, Graber PN. Two field studies examining the association between positive psychological capital and employee performance. Leadership \& Organization Development Journal, 2010; 31(5): 384-401.

4. Baharifar A, Javaheri-Kamel M, Ahmadi S. Moral behavior and organizational citizenship behavior: The effects of moral values, justice, and organizational commitment. Studies of Human Resource Management, 2011; 1(1): 23-42.
5. Bateman TS, Organ DW. Job satisfaction and the good soldier: The relationship between affect and employee citizenship. Academy of Management Journal, 1983; 26: 587-595.

6. Carr A. Positive Psychology. Tehran: Sokhan Publications, 2006.

7. Comeau DJ, Griffith RL. Structural interdependence, personality, and organizational citizenship behavior An examination of person-environment interaction. Personnel Review, 2005; 34(3): 310-330.

8. Golparvar M, Rafizadeh P. Trend for improving organizational citizenship behaviors through job attitudes, professional growth, leadership support, and empowerment. Basirat Periodical, 2009; 44(4): 27-47.

9. Hasanzadeh F. Positivism in Organizational Behavior. Tehran Tadbir, 2010.

10. Hoveyda R, Naderi N. Review of organizational citizenship behavior. Journal of Executive Management, 2012; 9(33): 103118.

11. Islami H, Sayar A. Organizational citizenship behavior. Tabir, 2007; 187, $56-60$.

12. Jung JY, Hong S. Organizational citizenship behavior (OCB), TQM and performance at the maquiladora. International Journal of Quality \& Reliability Management, 2008; 25(8): 793808.

13. Kim S. Public service motivation and organizational citizenship behavior in boorea. International Journal of Man Power, 2006; 27(8): 722-740

14. Konovsky MA, Pugh SD. Citizenship behavior and social exchange. Academy of Management Journal, 1994; 37(6): 656669.

15. Lara ZMD, Rodriguez TFE. Organizational anomie as moderator of the relationship between an unfavorable attitudinal environment and citizenship behavior (OCB): An empirical study among university administration and services personnel. Personnel Review, 2007; 36(6): 843-866.

16. Luthans F. Organization Behavior. MC Graw- Hill, 2008.

17. Luthans F, Youssef CM. Human, social, and now positive psychological capital management: investing in people for competitive advantage. Organizational Dynamics, 2004; 32(2): 143-160.

18. Luthans F, Youssef CM. Positive organizational behavior in the workplace the impact of hope, optimism, and resilience. Journal of Management, 2007; 33(5): 774-800.

19. Luthans F, Youssef CM, Avolio BJ. Psychological capital: developing the human competitive edge: Oxford university Press, 2007.

20. Luthans KW, Lebsack SA, Lebsack RR. Positivity in healthcare: relation of optimism to performance. Journal of Health Organization and Management, 2008; 22(2): 178-188.

21. Mahdad A, Dehghan A, Golparvar M, Shoja A. Relationship between Components of Psychological Health in Work Environment and Organizational Commitment and Organizational Trust among Employees. Periodical of Knowledge and Research in Applied Psychology, 2012; 48(2): 71-88.

22. Mahmoudi-Meymand M, Harandi A. A review of the interrelation between personnel's self-efficacy and 
organizational citizenship behavior, case study: Personnel of the Cultural Management Department of the Ministry of Science, Research and Technology. Organizational Resources Management Research, 2011; 153(1): 131-137.

23. Noor A. Examining organizational citizenship behavior as the outcome of organizational commitment: A study of universities teachers of Pakistan. Paper presented at the Proceedings of 2 nd CBRC, Lahore, Pakistan, 2009

24. Norman SM, Avey JB, Nimnicht JL, Pigeon NG. The interactive effects of psychological capital and organizational identity on employee organizational citizenship and deviance behaviors. Journal of Leadership \& Organizational Studies, 2010; 17(4): 380-391.

25. Organ DW, Podsakoff PM, MacKenzie SB. Organizational citizenship behavior: Its nature, antecedents, and consequences: SAGE Publications, 2006.

26. Pierce JL, Gardner DG, Cummings LL, Dunham RB Organization-based self-esteem: Construct definition, measurement, and validation. Academy of Management Journal of Applied Psychology, 2002; 32: 622-645.

27. Podsakoff PM, MacKenzie SB, Paine JB, Bachrach DG. Organizational citizenship behaviors: A critical review of the theoretical and empirical literature and suggestions for future research. Journal of Management, 2000; 26: 513-563.

28. Pursoltani-Zarandi H, Amirji R. Relationship between organizational commitment and organizational citizenship behavior PE teachers in Mashhad. Journal of Sport Management, 2012; 5(6): 127-147.
29. Robins A, Judge T. Organizational Behavior, 2010.

30. Salasel M, Kamkar M, Golparvar M. Relationship between organizational intelligence and its components and organizational citizenship behaviors among employees in SpadanEhiaGostaran Company. Periodical of Knowledge and Research in Applied Psychology, 2009; 44(2): 1-19.

31. Samavatyan H, Khani F, Nori A, Samsam-Shariat M. Big Five Personality relationship managers and supervisors with Organizational citizenship behaviors. Quarterly knowledge and research, 2011; 4: 36-48.

32. Shahnawaz GS, Jafri HS. Psychological capital as predictors of organizational commitment and organizational citizenship behavior. Journal of the Indian Academy of Applied Psychology, 2009; 35: 78-84.

33. Spector PE. Job Satisfaction: Application, Assessment, Causes, and Consequences. London: Sage, 1997.

34. Stoner JP, Perrewe PL, Munyon PT. The role of identity in extra-role behaviors: development of a conceptual model. Journal of Managerial Psychology, 2009; 26(2): 94-107.

35. Taghizadeh A. Relationship between Psychological Capital and Job Satisfaction and Organizational Commitment, Case Study: General Office of Education in Yazd Province. Alameh Tabatabaei University, Tehran, 2011.

36. Zhang X. Operationalization of corporate entrepreneurship and its performance implications in China: an empirical study. Journal of Chinese Entrepreneurship, 2008; 1(1): 8-20. 